\title{
ЭКЗОГЕННЫЕ ФАКТОРЫ ГИПОФЕРТИЛЬНОСТИ. КОМПОНЕНТЫ ПЛАСТМАСС - ФТАЛАТЫ
}

\author{
E.M. KOPEHEBA \\ к.б.н., старший научный \\ сотрудник лаборатории \\ репродуктивной \\ эндокринологии \\ ГУ «Институт проблем \\ эндокринной патологии \\ им. В.Я. Данилевского НАМН \\ Украины» \\ Н.А. КАРПЕНКО \\ к.б.н., заведующая \\ лабораторией репродуктивной \\ эндокринологии \\ ГУ «Институт проблем \\ эндокринной патологии \\ им. В.Я. Данилевского НАМН \\ Украины»
}

B.A. KA3AK

старщий лаборант лаборатории хроноэндокринологии ГУ «Институт проблем эндокринной патологии им. В.Я. Данилевского НАМН Украины»
$\mathrm{K}_{\mathrm{r}}^{\mathrm{a}}$

ак известно, неблагоприятное эколого-гигиеническое окружение может быть вызвано разнообразными причинами как минимум трех категорий: абиотическими, биологическими и антропогенными, т.е. деятельностью человека $[1,2]$. При этом на репродуктивные аспекты здоровья как женщин, так и мужчин все больше и больше отрицательно влияют антропогенные факторы [3-5], многие из которых приводят к гипофертильности в результате дисбаланса в функционировании эндокринной системы [6-8].

О влиянии экологических факторов на генеративный потенциал написано немало [1, 9-11], в том числе и нами [12-17]. К сожалению, с течением времени и в связи с развитием промышленности появляются новые факторы «потенциальной гипофертильногенности». Так, согласно данным литературы, некоторые компоненты пластических масс могут привести к повышению заболеваемости населения, в частности к росту эндокринной патологии. У некоторых пластификаторов, применяемых при производстве пластмасс, выявлены свойства репродуктивных токсикантов. Подобное обнаружено у фталатов - широко распространенных загрязнителей окружающей среды, которые являются компонентами многих бытовых предметов - от средств косметического ухода за кожей и духов до детских резиновых игрушек [18, 19].

Фталаты - группа химических соединений, представляющих собой сложные эфиры фталевой (ортофталевой) кислоты (дикарбоксибензолы) [18-21], которые обладают эндокриннодеструктивным действием [4], привлекающим в последнее время внимание врачей и ученых. В связи с актуальностью проблемы не только для производителей и потребителей изделий, содержащих фталаты, но и для медперсонала, врачей-гинекологов, андрологов, неонатологов, педиатров и других, целью настоящей работы было проведение анализа информационного потока для ответа на вопрос: могут ли фталаты, с воздействием которых большинство населения сталкивается в повседневной жизни, нанести вред репродуктивному здоровью человека?

\section{ПРИМЕНЕНИЕ ФТАЛАТОВ}

Основное применение фрталаты нашли в промышленности пластических масс, которая потребляет приблизительно 87\% всех сложных эфиров фрталевой кислоты для создания «мягкого поливинилхлорида». Оставшиеся $13 \%$ используются для производства лаков, эмульсионной краски, целлюлозы, полистирола, пигментов, синтетического и натурального каучука, смазочных материалов, полиамидов, средств борьбы с насекомыми, фриксаторов для закрепления запаха духов, замораживающих агентов для взрывчатых веществ и рабочих жидкостей для вакуумных насосов. Наиболее важными стандартными смягчителями среди фрталатов являются диоктилфрталат и диизононилфталат [5]

Диметилфталат и дибутилфталат нашли применение в многочисленных отраслях промышленности, включая текстильную, производство красителей, косметики и стекла. Так, диметилфрталат является основой для красителей и смягчителей в лаках для волос, а дибутилфталат часто используют в лаке для ногтей, для пропитки одежды, как средство от насекомых и как смягчитель в нитроцеллюлозных лаках, эластомерах, взрывчатых веществах и компонентах топлива твердотопливных ракет. Кроме того, диметилфталат является распространенным растворителем парфюмерных масел, фриксатором и смазочным агентом текстильных материалов, используется в производстве небьющегося стекла, типографских красок, различных покрытий и в качестве компонента полихлорвинилового пластизоля при производстве различных покрытий. Многие соединения диаллилфталата используются в электронных схемах, компьютерных и космических системах, в монтажных платах, изоляторах и потенциометрах, а также в военном деле.

Пластические массы, содержащие сложные эфиры фрталевой кислоты, часто используются (особенно диоктилфталат как пластификатор) в медицинском оборудовании, например в качестве емкостей для крови и трубок при гемодиализе, а также в стоматологии для изготовления зубных оттисковых материалов [6]. 
В пластических массах фрталаты не вступают в химическую реакцию с полимером, а распределяются между полимерными цепями и тем самым ослабляют межмолекулярные связи полимеров, увеличивая пластичность и облегчая переработку пластика в изделия, придавая высокую эластичность при низких температурах и устойчивость к деградации под действием света и тепла. Благодаря этому, а также низкой цене фрталаты используются для изготовления различных бытовых предметов [7].

Токсичность фрталатов обусловлена хроническим действием на различные системы организма. Отсутствие различий в коэффрициенте кумуляции в зависимости от дробности вводимой дозы указывает на высокую опасность хронического воздействия этих химических веществ. Так, показатели токсикометрии, полученные в хроническом эксперименте, позволяют отнести диметил- и диоктилфталат (наиболее изученные из фталатов) к классу высокотоксичных и высокоопасных веществ [25]. Важно то, что фрталаты, обладая эстрогеноподобным действием, оказывают значительное влияние на эндокринную систему.

Фталаты - не единственные компоненты пластмасс, которые влияют на здоровье человека. Весь жизненный цикл пластмасс - от производства до утилизации - связан с выделением веществ, и некоторые из них губительны как для здоровья человека, так и в целом для окружающей среды. В процессе производства и использования поливинилхлоридного пластика ядовитые вещества: хлор, дихлорэтан, винилхлорид, диоксин - выделяются в атмосферу и часто являются токсичными соединениями. К веществам, нарушающим фрункционирование эндокринной системы, относят также затвердители пластических масс. Так, например, бисфренол А, часто используемый при изготовлении пластиковых бутылок, стоматологических пломбировочных материалов и защитных покрытий металлической посуды, может нарушать работу репродуктивной (у экспериментальных животных он ускоряет половое созревание) и нервной систем (нарушает поведение), а также способствовать возникновению рака предстательной и молочной желез [8]. К разрушителям функционирования эндокринной системы относятся и многие ингибиторы горения, добавляемые в пластические массы. Например, полибромированный дифенол-эфир (ингибитор горения, обычный компонент мягкой мебели, автомобильных запчастей и домашней электроники) связывают с расстройством функционирования щитовидной железы, он же нарушает нормальную работу печени. При производстве ингибиторов и вследствие горения полимеров, в том числе бутылок, оплетки кабелей и т.д., выделяется большое количество диоксинов - наиболее токсичных органохлоринов $[1,4]$. По определению П.Ф. Забродского (цит. по Никитину, 2005), диоксины - полифункциональные, дисрегуляторные и дезаптогенные супертоксиканты, обладающие гормоноподобным действием. Итак, некоторые химические соединения, применяемые при производстве, использовании и утилизации пластических масс (затвердители, пластифрикаторы, ингибиторы горения и т.п.) не только разрушительно влияют на гормональную систему людей и животных, но и являются репротоксикантами, т.е. воздействующими на репродуктивную систему канцерогенами. Кроме того, и сам мономер поливинилхлоридных пластмасс - винилхлорид имеет прямую связь с нарушениями фрункций репродуктивных органов [9].

\section{ПУТИ ПОПАДАНИЯ ФТАЛАТОВ В ОРГАНИЗМ}

Фталаты являются распространенными загрязнителями мировой экосистемы, легко попадают и десятилетиями сохраняются во внешней среде, распространяясь с водой и воздушными массами на огромные расстояния, и обнаруживаются в осадках сточных вод [10]. В организм человека фрталаты попадают без его желания и ведома. Так как эти химические соединения не образуют ковалентных связей с другими компонентами пластмасс, они легко выбрасываются в окружающую среду. При этом с течением времени происходит разрушение синтетических материалов, что сопровождается ускорением высвобождения фрталатов [11]. Следует особо обратить внимание на тот фракт, что сложные эфиры фрталевой кислоты липофильны. При наличии жирной пищи или под воздействием высоких температур они обладают способностью переходить из материала, в котором находятся, непосредственно в соприкасающуюся с ними жидкость (воду, соки, молоко и другие пищевые продукты), хранящуюся в таре, содержащей их, а также непосредственно в организм, например при жевании детьми изделий из полихлорвинила - пустышек, игрушек и т.п. [6, 19].

Фталаты легко выщелачиваются и испаряются в пищу или атмоссреру из всевозможных упаковочных и медицинских материалов. Степень высвобождения и концентрация фталатов в растворе зависят от многих факторов, а именно: температуры, длительности контакта, перемешивания и т.д. Следствием таких медицинских процедур, как гемодиализ, трансфузия крови и плазмы, экстракорпоральная мембранная оксигенация, полное парентеральное питание или энтеральное зондовое питание является длительный контакт изделия с раствором. За счет этого отмечается высокое содержание фрталатов в этих растворах [11].

Фталаты обнаруживаются в крови и жировой клетчатке людей как имевших, так и не имевших контакта с ними. Более того, имеются сведения о том, что эти химические вещества обнаружены в загрязненных почвах, реках и водных организмах $[12,28]$. Благодаря низкому молекулярному весу фрталаты (диэтилфталат, дибутилфталат) могут всасываться через кожу [11]. Помимо трансдермального, установлен пищевой (например через рыбу, в которой они были обнаружены) и респираторный пути попадания этих химикатов в организм [6]. Сообщается и о трансплацентарном переносе соединений фрталевой кислоты и возможности попадания в организм с материнским молоком [12].

Согласно данным Агентства США по контролю за содержанием токсических веществ, ежедневно в организм жителей Америки в среднем поступает 2 мг фрталатов [1, 25, 40]. Итальянские ученые провели исследование концентрации фрталатов в материнском молоке. Оказалось, что в грудном молоке от 62 здоровых матерей во всех образцах присутствовали моноизобутилфрталат (медиана 18,8 мкг/л), моно-(2-этилгексил)-фрталат (медиана 8,4 мкг/л), тогда как моноизобутилфрталат (медиана 1,5 мкг/л) и монобензилфталат (медиана < 0,3 мкг/л) были найдены в 64,5 и 43,5\% из образцов соответственно [13]. При переливании крови с использованием одноразовых систем из пластика поступление таких химикалий достигает 200-300 мг [1, 25, 40]. Наиболее высокая концентрация фталатов наблюдается в детском возрасте [19]. 
ТАБЛИЦА 1.

Производное фталевой кислоты

Применение

Пластификатор, используемый при изготовлении поливинилхлоридов и других полимеров, например при производстве

Бис-(2-этилгексил)-фталат настила полов и крыш, материала с пленочным покрытием, медицинских приборов или упаковки для медицинских товаров

Пластификатор, используемый в полимерной продукции,

Бензилбутилфталат особенно в поливинилхлоридов для покрытий полов, в тканевых и кожаных покрытиях, герметиках, клеях, типографских красках

Пластификатор, основной областью применения которого явДибутилфталат ляются резинотехническая и лакокрасочная промышленность, производство кож и пленок

Два вида фрталатов - ди-(2-этилгексил)ТАБЛИЦА 1.

ФТАЛАТЫ, ОКАЗЫВАЮЩИЕ ТОКСИЧЕСКОЕ ДЕЙСТВИЕ НА РЕПРОДУКТИВНУЮ СИСТЕМУ фрталат (DEHP) и ди-(n-бутил)-фрталат (DBP) рассматриваются в европейских странах в качестве соединений второй категории, определяемых как химические вещества, уменьшающие фертильность, и которые следует считать вызывающими дефекты в развитии человека. В ноябре 2002 г. Европейское сообщество (ЕC) внесло поправки в Указание по косметике 76/768/EЕC. Ими предусмотрено не применять фталаты ввиду их влияния на репродуктивную систему, и особо обра-

ТАБЛИЦА 2.

\begin{tabular}{|c|c|}
\hline Обозначение & Фталаты \\
\hline BBP & Бутилфенилфталат \\
\hline DBP & Ди-(н-бутил)-фрталат \\
\hline DEHP & Ди-(2-этилгексил)-фрталат \\
\hline DEP & Диэтилфталат \\
\hline DHP & Ди-н-гексилфтталат \\
\hline DIDP & Диизодецилфрталат \\
\hline
\end{tabular}

ТАБЛИЦА 2.

НЕКОТОРЫЕ АББРЕВИАТУРЫ,

ИСПОЛЬЗУЕМЫЕ ДЛЯ ОБОЗНАЧЕНИЯ ПРИСУТСТВИЯ ФТАЛАТОВ В СОСТАВЕ ИЗДЕЛИЙ

щается внимание на такие виды, как DEHP и DBP [14]. И тем не менее, несмотря на то что фталаты негативно влияют на репродуктивную систему, они до сих пор широко используются в различных областях промышленности (табл. 1, 2) [15].

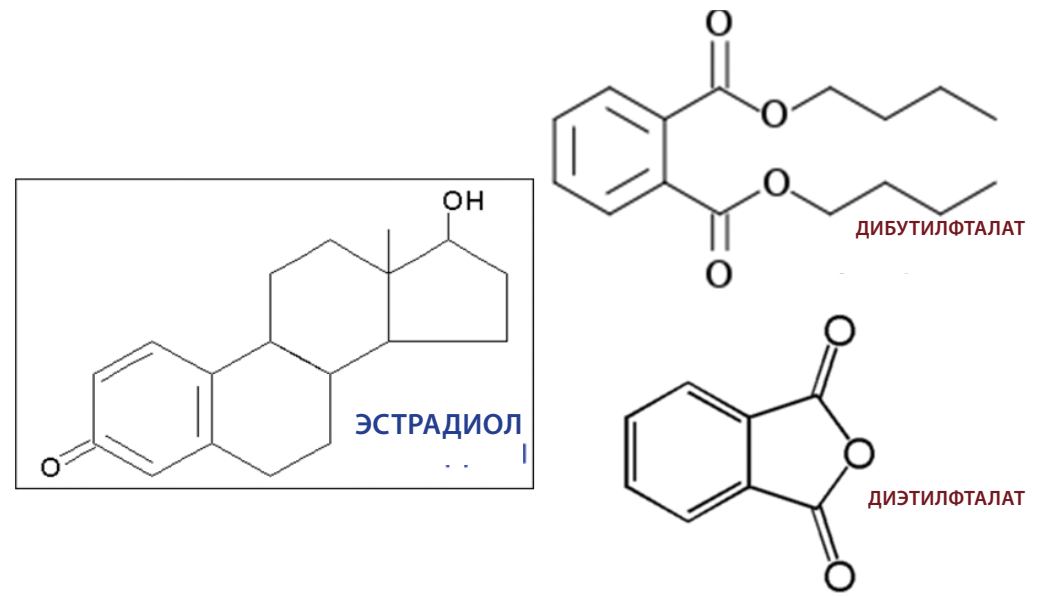

РИС. 1.

СТРУКТУРНЫЕ ФОРМУЛЫ ЭСТРАДИОЛА И НЕКОТОРЫХ ФТАЛАТОВ логичные запреты введены в США и в ЕС. Так, в США закон, запрещающий применение фрталатов, подписан в 2008 г. [16].

Вопрос о запрете применения фрталатов в косметике и игрушках весьма актуален, поскольку некоторые из них, в норме не входящие в состав тканей организма, обнаружены в человеческом теле [17].

\section{ВЛИЯНИЕ ФТАЛАТОВ \\ НА ЖЕНСКИЙ ОРГАНИЗМ}

Фталаты способны связываться с рецепторами к эстрогенам. Обнаружено, что у женщин репродуктивного возраста концентрация в крови фрталатов является наиболее высокой по сравнению с другими половозрастными группами [1].

А.И. Никитин в своей монографии о вредных фракторах среды описывает результаты исследования Jobling et al., которые изучали эстрогенные свойства фрталатов на культуре клеток рака молочной железы. Ученые обнаружили эстрогенные свойства у десяти видов производных фрталевой кислоты из 20, изученных ими. При этом активность некоторых из них была близка к активности природного женского полового гормона эстрадиола $[1,18]$.

Содержание моноэфиров бензил-, бутил-, этил- и этилгексилфталатов в моче людей от 7,3 до 211 нг/мл [1]. В ретроспективном биомониторинговом изучении за девять лет (1988-2003) суточных образцов мочи (в основном у студентов 20-29 лет, 326 женщин и 308 мужчин), взятых из немецкого экологического банка образцов человеческих тканей, проанализировали уровень концентрации первоначальных и/или вторичных метаболитов различных производных фрталевой кислоты ди-n-бутилфрталата, диизобутилфрталата, бутилбензилфталата, диэтилгексилфталата и диизононилфталата. Повсеместное распространение фрталатов в последние 20 лет отразилось на результатах мониторинга. Как оказалось, более 98\% образцов мочи содержали все пять соединений и на протяжении всех лет. Так, концентрация некоторых фрталатов была неизменной, а медиана содержания диизононилфталата повышалась. Например, в 1988 г. таковая составляла 1,1 мкг/кг массы тела в сутки, в 2003 г. - 1,4 мкг/кг. Ежедневная экскреция этого вида фрталата беспрерывно увеличивалась, имея самые низкие средние значения - 0,2 мкг/кг массы тела в день в 1988 г. и самую высокую медиану (вдвое выше) - в 2003 г. [19].

Авторы предполагают, что тенденции изменения клиренса фрталатов, возможно, связаны с модернизацией производства и образом использования этих химикалий.

Следует отметить, что в образцах, полученных от женщин, было обнаружено значительно 
повышенное ежедневное поглощение ди-n-бутилфталата. Причем в 14\% случав наблюдали концентрацию ди-nбутилфрталата выше безопасного значения, рекомендованного европейскими специалистами (EFSA), - 10 мкг/кг массы тела в день) [38].

Высокий уровень фрталатов в моче женщин прямо коррелирует:

с с частотой нарушения менструального цикла;

с с осложнениями беременности - анемией, токсемией, преэклампсией, невынашиванием [1].

В эксперименте действие гонадотоксичных ксенобиотиков (к которым относятся и фрталаты) у самок крыс вызывает гонадо- и гаметотоксические эффректы, проявляющиеся в снижении уровня секреции эстрадиола, отсутствии его преовуляторного подъема, удлинении фраз диэструс и метаэструс в эстральном цикле, появлении ановуляторных циклов. Все это влечет за собой нарушения репродуктивного здоровья, приводящего в конечном итоге к снижению плодовитости. При изучении способности дибутилфталата влиять на фрертильность в опытах на самках крыс (в течение двух месяцев во время пубертатного периода в дозе 12 или 50 мг/кг массы тела в день) обнаружено, что их потомки имели задержку полового созревания (снижение относительной массы семенников, открытия влагалища и начало первого эструса) [20]. Имеются сообщения о нарушении фертильности крыс при повышенной концентрации фрталатов в питьевой воде (1 мг/л) [1].

Наиболее уязвимыми для повреждающих фракторов женские половые клетки становятся в периовуляторном периоде полового цикла, совпадающем у человека и большинства млекопитающих с заключительными этапами гаметогенеза. Ведущим в механизме наблюдающихся при этом расстройств является, вероятно, десинхронизация процессов созревания ооцитов и овуляции. С учетом этих данных периовуляторный период полового цикла следует рассматривать как один из особо опасных периодов относительно экзогенных воздействий [28].

В эксперименте на самках крыс и кроликов доказано, что под влиянием фрталатов подавляется секреция эстрадиола, происходит супрессия овуляции, наблюдаются расстройства эстрального цикла, нарушение фолликулогенеза с формированием поликистоза яичников [21].

Если говорить о потенциальных рисках, то необходимо помнить, что под влиянием репротоксикантов у женщин может повышаться частота преждевременных родов, новорожденные могут иметь сниженную массу тела, а у рожениц может происходить сокращение сроков лактации. Кроме того, высоким является и риск возникновения рака молочной железы.

Установлено, что производные фрталевой кислоты способны проникать в различные ткани организма женщины: в цервикальную слизь, фролликулярную жидкость яичников, амниотическую жидкость и грудное молоко $[1,22,23]$ Поэтому не зря в обществе имеется выраженный интерес к безопасному количеству фрталатов, получаемых новорожденным с грудным молоком или молочными смесями для вскармливания. K сожалению, в настоящее время по этому вопросу нет единого мнения [24]. Однако уже никто не сомневается, что младенцы представляют собой группу риска, поскольку они подвергаются воздействию фталатов сразу несколькими различными путями, и в силу критич- ности возрастного периода последствия вреда могут проявиться не сразу [25].

Еще одним местом приложения длительного действия фрталатов на организм женщины может быть возникновение так называемого синдрома преждевременного истощения яичников (преждевременной менопаузы) [1, 26, 27].

Таким образом, фрталаты представляют собой потенциальную угрозу репродуктивному здоровью и требуют мониторинга в сфрерах, где женщины детородного возраста могут подвергаться их длительной или интенсивной экспозиции.

\section{ВЛИЯНИЕ НА МУЖСКОЙ ОРГАНИЗМ}

Следует подчеркнуть, что многие гормоноподобные ксенобиотики обладают эстрогенным и антиандрогенным действием. И это прежде всего сказалось на лицах мужского пола [3, 28-31]. Среди прочих френоменов отмечаются снижение полового влечения, рост эректильной дисфункции. И уже никого не удивляет снижение средней концентрации сперматозоидов за период 1938-1990 гг. в среднем со 113 до 60 млн/мл, а также то, что объем эякулята уменьшился на 0,7 мл. Вероятно, в этот процесс определенную лепту вносят и производные фрталевой кислоты.

Фталаты, являясь эндокринными разрушителями, воздействуют на мужской организм, вызывая нарушения в соматическом развитии, половом созревании и поведении, оказывая феминизирующий эффект на гениталии мальчиков (гипоспадия, недоразвитие полового члена, крипторхизм) [31].

Под действием экзогенного введения фрталатов у самцов лабораторных животных изменялась реакция клеток Сертоли на фолликулостимулирующий гормон (ФСГ), снижалась концентрация и подвижность сперматозоидов, подобные изменения наблюдались и у человека. Одной из причин поражений половой системы плодов мужского пола является снижение продукции тестостерона вследствие антиандрогенного действия фрталатов [1, 28, 29].

Антиандрогенное действие фрталатов подтверждено не только in vivo, но и в исследованиях на культуре ткани яичек и мошонки. При этом потенциальная возможность снижения уровня мужского полового гормона в этих тканях под влиянием моноэфиров фталевой кислоты (монобутилфрталата и моно-(2-этилгексил)-фрталата соответствовала таковой эстрадиола [30].

Часто основой пороков половой системы самцов является снижение продукции тестостерона эмбриональными яичками, вызванное действием эндокринных дисрапторов. Так, фталаты, воздействуя на плод, оказывают феминизирующий эффект на гениталии мальчиков, вызывают нарушения в соматическом развитии, половом созревании и поведении детей [31]. Производные фрталевой кислоты, содержавшиеся в крови матерей мальчиков, действовали подобно эстрогенам, нарушая половое развитие плодов мужского пола, что проявлялось в виде недоразвития полового члена, неопускания яичек в мошонку и т.п. [31].

Согласно G. Shonfelder et al. [1, 32], фрталаты способны преодолевать плацентарный барьер. При применении диэтилгексил- и дибутилфталатов беременным самкам крыс и мышей было обнаружено повышение частоты пренатальной гибели плодов, мертворождаемости, врожденных пороков, в том числе половой системы (крипторхизма и гипоспадии); снижение веса плодов, у самцов - веса яичек и 
эпидидимиса; уменьшение диаметра семенных канальцев и числа клеток Сертоли; в дальнейшем снижение продукции сперматозоидов у потомства [1, 33, 34]. По мнению авторов, причиной пороков половой системы самцов является снижение продукции тестостерона эмбриональными яичками вследствие антиандрогенного действия производных фрталевой кислоты [28].

Так, например, в экспериментальном 90-дневном исследовании введения DEHP самцам крыс в дозе 0,2; 1,0 и 2,0\% в диете выявлено увеличение относительной массы яичек крыс. Гистопатологические изменения в семенниках под влиянием DEHP характеризовались достоверным сокращением диаметра семявыносящих канальцев. Зародышевый эпителий состоял только из клеток Сертоли, сперматогоний и небольшого количества сперматоцитов, что приводило к снижению сперматогенеза. Соединительная ткань и клетки Лейдига визуально были не изменены.

Исследования по изучению эффектов DBP показали, что введение этого вещества в дозе 500 и 1000 мг/кг самцам крыс приводило к существенному сокращению относительной массы яичек в течение 4-6 дней. Гистологическая картина повреждений семенника под влиянием DBP была подобна таковой после обработки DEHP. У самцов под воздействием фталатов изменяется реакция клеток Сертоли на действие ФСГ, нарушается сперматогенез, снижается концентрация и подвижность сперматозоидов. DEHP или диметоксиэтилфталат при ежедневном (в течение 6 нед) внутрибрюшинном введении мышам (250 мг/кг) также значительно уменьшал относительную массу семенников.

\section{ВЛИЯНИЕ ФТАЛАТОВ НА ФУНКЦИОНИРОВАНИЕ РЕПРОДУКТИВНОЙ СИСТЕМЫ ОСОБЕЙ, ПОДВЕРГНУТЫХ В РАННИЕ ПЕРИОДЫ \\ РАЗВИТИЯ ИХ ДЕЙСТВИЮ}

Эти химические вещества могут поражать детский организм еще на стадии его формирования в утробе матери, вызывая нарушения в работе репродуктивных органов.

Фталаты, воздействуя на детский организм, вызывают нарушения:

в соматическом развитии;

в половом созревании;

в поведении детей.

У матерей, в чьей крови было обнаружено большое количество фрталатов на последних месяцах беременности, рождались дети, у которых впоследствии возникало много поведенческих проблем.

В настоящее время уже не вызывает сомнения тот фракт, что химические вещества, разрушающие некоторые гормоны, могут повлиять на половые признаки человеческого зародыша, сделать более «женственным» эмбрион мужской особи, находящийся в утробе матери. У сыновей женщин, организм которых во время беременности подвергался воздействию фрталатов, половые органы сформировались уменьшенными.

Как уже говорилось выше, фрталаты способны преодолевать плацентарный барьер. В экспериментальных работах доказано, что при использовании диэтилгексил- и дибутилфрталатов у беременных самок крыс и мышей было обнаружено повышение частоты:

пренатальной гибели плодов;

мертворождаемости; врожденных пороков;

развития пороков половой системы;

крипторхизма и гипоспадии.

Кроме того:

с снижение веса плодов;

5 у самцов снижение веса яичек и эпидидимиса, уменьшение диаметра семенных канальцев и числа клеток Сертоли, в дальнейшем - снижение продукции сперматозоидов у потомства.

Особо опасно действие фрталатов, как, впрочем, и других эндокринных дисрупторов, в период так называемых «окон развития» [35]. У женщин с 8-й по 24-ю неделю беременности у плода активно развиваются мужские половые органы и мозг. Эти процессы происходят под влиянием мужского полового гормона - тестостерона. C 7-8-й недели беременности эмбрион начинает сам синтезировать тестостерон, благодаря которому происходит фрормирование первичных и вторичных половых признаков. В этот период на него действует масса веществ, препятствующих нормальной выработке тестостерона. Специалисты называют эти химикаты эндокринными дисрупторами (деструкторами) - они мешают нормальной работе гормонов и прежде всего направлены против тестостерона. Практически все они по действию похожи на эстрогены (женские половые гормоны). Фталаты относятся именно к таким веществам [36, 37]. Они оказывают отрицательное влияние на клетки Лейдига, подавляя синтез тестостерона либо блокируя его действие, вызывая недоразвитие половых органов, разрушая таким образом запрограммированную цепь событий онтогенеза, необходимую для нормального сомато-сексуального развития.

Особи в критические периоды являются группой высокого риска в отношении токсического влияния фталатов. Если мужской организм во время «окон развития» испытывает избыток эстрогенов либо антиандрогенов, то фрормирование первичных и вторичных половых признаков идет по женскому типу [3]. Вследствие этого в будущем возможны явные и не очень заметные пороки репродуктивной системы, появление дефектных сперматозоидов, не исключено и развитие рака яичка. Это и происходит при действии фталатов в критические периоды развития и потенциально способствует развитию репродуктопатий. Клиническое проявление таких состояний называется «фрталатовым синдромом», который иногда называют «датским» [21].

Этот синдром включает множество биохимических изменений, которые вовлекают мужскую репродуктивную систему, в том числе несформировавшиеся яички, ненормальность развития полового члена, при котором уретра открывается на нижней стороне (гипоспадия), асинхронии полового созревания, рак яичка и сниженное количество спермы. Влияние фрталатов приводит к нарушению нормального развития клеток Лейдига и клеток Сертоли [38]. Проявления фрталатного синдрома у мужских особей описано под влиянием диэтилгексилфтталата, диизобутилфталата, диизогептилфталата и диизононилфталата. Эффект наблюдается при обработке в различных дозах. Например, применение DEHP в дозе 100; 300; 500; 625; 750 или 875 мг/кг В день на 14-18-й день беременности аутбредных крыс CD (Sprague Dawley) приводило к гипотестостеронемии и снижению уровня инсулиноподобного фактора роста 
3-го (ИФР-3) [39]. В то же время связывание ИФР-3 с определенным рецептором вместе с тестостероном является пусковым механизмом, который заставляет опускаться яички из брюшной полости, где они развивались во время беременности, в мошонку вне тела. Тем самым в результате влияния фрталатов на эти клетки происходит нарушение формирования и нисхождения яичек [40].

Следует отметить, что раннее воздействие фрталатов может привести к ранней андропаузе. Так, пероральное введение ди(2-этилгексил)-фрталата при концентрациях 0,$075 ; 0,75 ; 1,5$ и 5,0\% крысам в течение 90 дней привело к трубчатой атрофии и относящемуся к вырождению яичка, напоминающему старческие изменения [41].

Действие фрталатов не ограничивается критическими периодами («окнами») развития маскулинизации. Менее выраженные отсроченные во времени изменения наблюдаются при воздействии не только в критический период развития особи, но и в последующих этапах сомато-полового развития.

В частности, попадание фрталатов (DEHP в дозе 1 мг/кг массы тела) в организм самцов крыс во время последних 10 дней подсосного периода приводило при достижении животными половозрелости к снижению уровня тестостерона, лютеинизирующего гормона и ФСГ, поражению морфологического строения тестикул, замедлению скорости движения сперматозоидов и снижению их количества [52]

Действуя в период молочного вскармливания, фрталаты способны извратить нормальную программу полового развития. Ежедневное их попадание в организм малышей, вероятно, является риском для здоровья. Тем более что в экспериментах на животных доказано, что смеси, содержащие такие химикалии, могут воздействовать на дифференцирование и функцию воспроизводительной системы. А поскольку молоко - главный источник питания для младенцев, знание уровней фталатов в молоке для вскармливания важно для определения риска и предотвращения последствий патологического воздействия [42].

Таким образом, возможность попадания фрталатов в организм ребенка должна быть строго регламентированной не только технологически, но и законодательно, на что неоднократно обращается внимание в международных документах [43].

\section{ФТАЛАТЫ И ГОРМОНАЛЬНЫЙ ДИСБАЛАНС ОРГАНИЗМА}

Из наиболее обсуждаемых в литературе влияний фрталатов на уровень гормонов является уже вышеописанное воздействие этих поллютантов на содержание мужских, женских и го- надотропных гормонов. Однако фрталаты, изменяя гормональный баланс в организме, могут отрицательно влиять на развитие не только половой системы, но и щитовидной железы у людей и животных, провоцируя и генитальные отклонения, например неправильное фрормирование и органов мочеполовой системы, и нарушение тиреоидной фрункции [44, 45]. Ученые предостерегают о возможном действии фрталатов во время беременности на дальнейшее умственное и психомоторное развитие, особенно лиц мужского пола [46]. Поступление фрталатов в организм может вызвать повышение уровня пролактина [47]. Не следует забывать также и о том, что наблюдающийся при действии эндокринных дисрапторов гормональный дисбаланс может способствовать активации неопластических процессов органов репродуктивной системы $[4,8,58]$.

Подводя итог вышеизложенному, можно сделать вывод, что фталаты являются гормоноподобными ксенобиотиками, которые по эффекту, оказываемому на организм, являются эндокринными деструкторами (дисрапторами). Фталаты могут воздействовать на репродуктивную систему человека и животных, нарушая гормональный баланс организма, провоцируя развитие генитальных отклонений, неправильное формирование и функционирование мочеполовой системы. В основе их действия лежит способность вмешиваться в репродуктивный процесс путем связывания со специфическими рецепторами половых стероидов, маскируясь подестественные половые гормоны, блокируя или воспроизводя действие последних, либо извращая их эффрект [48]. Последнее обусловлено тем, что (как и стероидные гормоны) многие из гормоноподобных ксенобиотиков по химической структуре являются производными френола или содержат (как фрталаты) эквивалент френола. Это позволяет им связываться с рецепторами арил-гетероциклических углеводородов $[4,71]$, изменяя реализацию действия эндогенных гормонов, нарушая природное течение биологических процессов, лежащих в основе воспроизводства. Кроме того, фрталевые соли и эфиры обладают способностью кумулироваться и проявлять аддитивный эффект при совместном действии с другими веществами, способными влиять на репродуктивную систему $[19,22]$. При неэффрективном управлении техническими объектами и технологическими процессами производства, а также неадекватном использовании пластмасс и компонентов их производства либо утилизации могут возникать экологически детерминированные патологии репродуктивной системы.

Список литературы в количестве 48 источников представлен на сайте www.reproduct-endo.com.ua

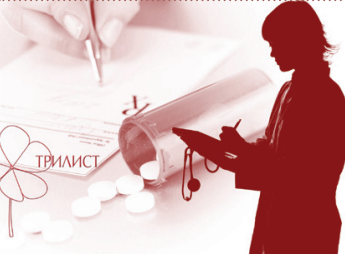

Фталаты - не единственные компоненты пластмасс, которые влияют на здоровье человека. Весь жизненный цикл пластмасс - от производства до утилизации связан с выделением веществ, и некоторые из них губительны как для здоровья человека, так и в целом для окружающей среды 